\title{
Composição do leite de vacas Holandesas em pastejo de azevém com a utilização do trevo branco como fonte proteica
}

\author{
[Milk composition of Holstein cows grazing ryegrass with the use of white clover as a protein source] \\ R.H. Krolow ${ }^{1}$, M.A. Silva ${ }^{2}$, N.R. Paim ${ }^{2}$, R.B. Medeiros ${ }^{2}$, H.L. Gonzalez ${ }^{3}$ \\ ${ }^{1}$ UNIPAMPA - Campus Itaqui - Itaqui, RS \\ ${ }^{2}$ Faculdade de Agronomia - Universidade Federal do Rio Grande do Sul - Porto Alegre, RS \\ ${ }^{3}$ Faculdade de Veterinária - Universidade Federal de Pelotas - Pelotas, RS
}

\begin{abstract}
RESUMO
Avaliou-se a composição do leite de animais em pastejo de azevém (Lolium multiflorum Lam.) alimentados com trevo branco (Trifolium repens L.) como substituição ao componente proteico da ração (farelo de soja), em porcentagens de proteína, lactose, sólidos totais e contagem de células somáticas. Utilizaram-se dois grupos com oito vacas da raça Holandesa, agrupados por produção, período de lactação e peso corporal, em delineamento em blocos ao acaso. Um grupo recebeu, diariamente, $3 \mathrm{~kg}$ de suplemento energético subtraído de farelo de soja e teve acesso à pastagem de trevo branco por, aproximadamente, 2,5 horas (TB); o outro recebeu o mesmo suplemento, adicionado de quantidade de proteína equivalente ao consumo diário no tratamento anterior via trevo, na forma de farelo de soja (FS). Foram observadas diferenças significativas para teor de proteína e lactose, sendo os maiores valores encontrados de proteína em TB (3,02\%) e de lactose em FS (4,64\%). Para as demais variáveis não houve diferença, com valores de 10,40 e 10,39\% de sólidos totais e 182,88 e 153,53 (x1000) células somáticas em TB e FS, respectivamente, mostrando que a utilização dessa fonte alternativa de proteína foi eficiente.
\end{abstract}

Palavras-chave: pastejo, proteína, qualidade do leite, suplementação

\begin{abstract}
Was evaluated the composition of milk from animals grazing annual ryegrass (Lolium multiflorum Lam.) fed with white clover (Trifolium repens L.), as a replacement for the protein component of the ration (soybean meal), in percentages of protein, lactose, total solids and somatic cell counts. Were used two groups with eight Holstein cows, grouped by production, lactation period and body weight, in a randomized block design. One group received $3 \mathrm{~kg}$ of energetic supplement subtracted of soybean meal daily and had access to the white clover pasture for approximately 2.5 hours (TB); the other received the same supplement, added of a quantity of protein equivalent to daily intake in previous treatment via white clover, in the form of soybean meal (FS). Significant differences were observed for protein and lactose content, with the highest values found for protein on TB (3.02\%) and lactose on FS (4.64\%). For the other variables there was no difference, with values from 10.40 and $10.39 \%$ of total solids and 182.88 and 153.53 (x1000) somatic cells on TB and FS respectively, showing that the use of this alternative source of protein was efficient.
\end{abstract}

Keywords: grazing, milk quality, protein, suplementation

\section{INTRODUÇÃO}

Os debates recentes em torno das estratégias para o desenvolvimento de sistemas de produção

Recebido em 20 de julho de 2011

Aceito em 19 de julho de 2012

E-mail: rodrigokrolow@unipampa.edu.br

Apoio financeiro: CNPq e Prefeitura Municipal de Camargo, RS leiteira sustentáveis têm apontado para a necessidade de se considerar, além da produtividade, enfatizada no passado, outros indicadores como a estabilidade e a sustentabilidade da produção (Carvalho et al., 
2009). Normalmente, quanto mais intensificado for o sistema de produção, maiores serão os custos de produção, menor a margem de lucro na comercialização do produto e menor a rentabilidade da propriedade (Vilela et al., 2005; Vilela et al., 2007). Por conseguinte, observa-se grande interesse pelo desenvolvimento de novas tecnologias na produção animal e o uso de pastagens para a obtenção de produtos mais competitivos e de qualidade (Silva et al., 2005).

A sustentabilidade ambiental dos sistemas de produção também passa pela valorização do uso de forragem pastejada, que tem como consequência a menor contaminação do solo e das águas (Ribeiro Filho et al., 2009).

A qualidade do leite pode ser afetada por vários fatores associados ao manejo, à sanidade, à alimentação e ao potencial genético dos animais (Andrade et al., 2007). A alimentação da vaca pode influenciar no valor nutritivo do leite e dos derivados lácteos, como o queijo, uma vez que alimentos saudáveis são cada vez mais procurados pelos consumidores (Fernandes et al., 2008). O manejo da nutrição constitui, então, a principal estratégia para alterar a composição do leite (Mattos e Pedroso, 2005) a fim de atender distintas demandas de mercado. Neste aspecto, a manipulação da dieta, com o intuito de alterar a produção e a composição do leite, vem se tornando muito comum dentro da atividade leiteira (Oliveira et al., 2007).

A crescente demanda pela utilização racional e sustentável dos recursos alimentícios em todo o mundo tem exercido pressão cada vez maior sobre a necessidade de se pesquisar a utilização de fontes alimentícias alternativas na nutrição animal. Sendo assim, a busca por alternativas para substituir os grãos na alimentação de ruminantes assume grande importância (Pedroso et al., 2009). O custo dessas fontes tradicionais de alimentos tem se tornado limitante dos sistemas de produção animal, e a inclusão de fontes proteicas alternativas na alimentação de vacas em lactação tem como principal objetivo baixar os custos de alimentação, mantendo os níveis de produção e a composição do leite.

A correta utilização dos suplementos proteicos tem um impacto considerável na rentabilidade do sistema de produção de leite, pois as diferentes fontes de proteína representam parcela considerável do custo das dietas para vacas em lactação (Santos et al., 2003). Na média, os concentrados comerciais utilizados nas fazendas brasileiras apresentam teores de 20 a $25 \%$ de proteína bruta $(\mathrm{PB})$ na matéria seca (Santos e Juchem, 2001), o que pode ser excessivo em alguns casos. A utilização de altas doses de concentrados, ou altos teores de proteína no concentrado, pode prejudicar o desempenho e até aumentar a quantidade de nitrogênio excretado na urina. Ainda, os concentrados proteicos são caros e a grande quantidade de nitrogênio excretado pode gerar prejuízos para o ambiente (Castillo et al., 2000; Ryan et al., 2011).

Para Santos et al. (2003), a utilização de concentrados com 16 a $18 \%$ de PB, ao invés de formulações com 20 a $24 \%$ de PB, normalmente observadas em sistemas que utilizam pastagens de qualidade como base da alimentação de vacas em lactação, pode diminuir o custo de suplementação, sem comprometer a produção.

No Brasil, o farelo de soja é a principal fonte proteica em dietas para vacas leiteiras suplementadas com concentrado, sendo considerado uma proteína de excelente qualidade, que apresenta alta degradabilidade ruminal, porém sua inclusão pode resultar em maior custo dietético.

A utilização de outras fontes proteicas em substituição ao farelo de soja, desde que elas não comprometam o desempenho animal, pode ser uma estratégia viável para a redução dos custos. No entanto, essas fontes proteicas alternativas devem ser eficientes, seguras e econômicas, permitindo desempenhos produtivos similares aos animais alimentados com dietas tradicionais (Pina et al., 2006).

Nesse sentido, Martinez e López (1991) desenvolveram um experimento com o intuito de determinar suplementos para vacas leiteiras para a mantença da produção e demonstraram que o emprego de ureia ou trevo branco (Trifolium repens L.), em substituição parcial ao farelo de soja, apresentou a mesma eficiência na produção de leite, com vantagens econômicas para o trevo branco.

Em pesquisa mais recente, Fontaneli et al. (2005) estudaram sistemas de produção de leite, em confinamento tradicional ou em pastagens com 
suplementação, tendo como base forrageira, em um sistema em pastagem, o trevo encarnado (Trifolium incarnatum L.) e o trevo vermelho (Trifolium pratense L.) como espécies leguminosas de clima temperado, para vacas Holandesas suplementadas sem o farelo de soja no concentrado. Os autores observaram a possibilidade de obtenção de mesmo rendimento e composição do leite, porém com vantagem econômica, em termos de custo de produção de leite, para o sistema em pastagem, quando comparado ao confinamento.

Um aspecto importante em relação ao uso de leguminosas é a economia no uso de suplementos, tanto em quantidade fornecida quanto no teor de proteína do suplemento. Com boas quantidades de trevo nas pastagens, a utilização de concentrado pode não ser vantajosa devido ao seu custo (Wilkins et al., 1994).

Muitas informações se têm sobre a produção e a digestão de vacas leiteiras em pastagens de clima temperado (Stockdale, 2000; Bargo et al., 2001; Peyraud e Delaby, 2001; Bargo et al., 2002). Todavia, os trabalhos realizados para avaliação dos parâmetros qualitativos do leite, seguidamente, fazem referência àqueles publicados no exterior.

Deste modo, com a finalidade de obter mais informações sobre a utilização de alimento proteico para vacas leiteiras, oriundo de pastagens de qualidade, comparou-se a eficiência da substituição de farelo de soja por pastejo em trevo branco - uma fonte alternativa de proteína - sobre a qualidade do leite produzido por animais em pastagem de azevém (Lolium multiflorum Lam.).

\section{MATERIAL E MÉTODOS}

O presente trabalho foi desenvolvido em um estabelecimento particular de pecuária leiteira, localizado no município de Camargo, na bacia leiteira de Passo Fundo - Marau/RS, escolhido para tal em razão da representatividade de seus sistemas produtivos, baseados principalmente na produção leiteira, de suínos e de aves, e na cultura de soja. O clima predominante na região, segundo a classificação de Köeppen (Moreno, 1961), é do tipo subtropical úmido Cfa, com temperaturas médias entre 16 e $18^{\circ} \mathrm{C}$, temperaturas máximas médias entre 22 e $25^{\circ} \mathrm{C}$ e mínimas entre 10 e $13^{\circ} \mathrm{C}$ (IPAGRO, 1989). Apresenta precipitação pluvial bem distribuída ao longo do ano e inverno marcado por fortes geadas e eventuais nevascas.

Para a realização do experimento, foram utilizadas áreas de pastagens da propriedade, cultivadas com azevém anual, proveniente de ressemeadura natural, muito comum e usual na região de estudo, e trevo branco, implantado no ano anterior. Procedeu-se à adubação da área experimental de trevo branco, para a reposição de nutrientes, conforme a recomendação obtida pela análise do solo. Na área de azevém, após cada período de pastejo foram aplicados $50 \mathrm{~kg}$ de ureia $\mathrm{ha}^{-1}$. Junto às áreas experimentais, dispunha-se de um galpão para pernoite e arraçoamento dos animais, de uma sala de ordenha do tipo espinha de peixe e demais instalações, como resfriador, bebedouros, etc.

Foram utilizadas 16 vacas da raça Holandesa, selecionadas no rebanho da propriedade em função da produção de leite, do período de lactação e do peso vivo individual. Após a estratificação realizada com base nestes três quesitos, os animais, distribuídos ao acaso em dois grupos (tratamentos TB e FS), foram mantidos, durante todo o experimento, em piquetes separados. Os animais apresentavam-se, em média, com 2,12 e 2,07 meses de lactação para os tratamentos TB e FS, respectivamente, no início das avaliações.

No TB, os animais foram mantidos em pastagem de azevém, por determinado período de tempo durante o dia ( \pm 5 horas) e com acesso controlado à pastagem de trevo branco $( \pm 2,5$ horas $)$ como fonte de alimentação proteica; no $\mathrm{FS}$, foram mantidos em pastagem de azevém pelo mesmo período e receberam farelo de soja como fonte proteica - na quantidade de $1,6 \mathrm{~kg}$ animal ${ }^{-1} \mathrm{dia}^{-1}-$ calculada pela estimativa do consumo diário de proteína pelos animais no tratamento anterior via trevo branco, considerando-se o teor de proteína e a digestibilidade do trevo e do farelo. Todos os animais receberam suplementação energética $3 \mathrm{~kg}$ animal ${ }^{-1} \mathrm{dia}^{-1}$ - constituída de farelo de trigo, farelo de milho, casca de soja e sal mineral. Esse procedimento visou comparar uma fonte alternativa de alimento proteico (TB) com um sistema controle (FS) que reproduz, em sua quase totalidade, o modelo tecnológico adotado 
pela propriedade e comumente utilizado na região pela maioria dos produtores de leite.

Os animais foram submetidos, previamente, a um período de 15 dias de adaptação ao manejo nutricional utilizado durante o período experimental, que perdurou de agosto a outubro de 2004, totalizando cinco períodos de avaliação, realizado a cada 15 dias, em um delineamento em blocos ao acaso.

Adotou-se o pastejo rotativo em faixas utilizadas por um dia, seguindo o manejo normal da propriedade, realizada da seguinte maneira: após a ordenha da manhã, os animais eram conduzidos à pastagem de azevém, onde permaneciam por, aproximadamente, cinco horas; em seguida, eram levados a um local onde tinham acesso à água $\mathrm{e}$ sombra. Os animais do tratamento FS permaneciam nesse local, enquanto os do TB eram levados até a pastagem de trevo branco, onde permaneciam por, aproximadamente, 2,5 horas, até a ordenha da tarde. Na sequência, todos os animais pernoitavam em um galpão. $\mathrm{O}$ tempo de permanência de 2,5 horas foi determinado em função do tamanho da área disponível de trevo branco destinada ao pastejo do grupo de animais.

Durante a utilização das pastagens, procurou-se a manutenção de disponibilidades de forragem, na entrada e na saída dos animais de cada piquete, diariamente, a fim de otimizar utilizações subsequentes e prolongar ao máximo o período de uso da pastagem, baseando-se, principalmente, na altura do resíduo. A disponibilidade média na pastagem de azevém manteve-se em 1271,20 e $1099,00 \mathrm{~kg} \mathrm{ha}^{-1}$ na entrada e 563,68 e $385,50 \mathrm{~kg} \mathrm{ha}^{-1}$ na saída dos animais para TB e FS, respectivamente. A pastagem de trevo branco continha, em média, $80,4 \%$ da espécie de trevo, obtidas pela amostragem da área e pela separação botânica.

A composição individual do leite foi obtida 48h após o pastejo dos animais em cada faixa, durante dois dias consecutivos - quatro ordenhas subsequentes -, no intervalo de 15 dias. Com equipamento acoplado ao sistema de ordenhadeiras, eram retiradas amostras de leite para a determinação de: gordura, proteína, lactose e sólidos totais e a contagem de células somáticas (CCS). O equipamento era constituído de amostradores do tipo True test, específico para tal controle. As amostras de leite eram enviadas ao laboratório, onde foram feitas as análises para a determinação dos teores dos componentes citados.

Os dados obtidos foram submetidos à análise multivariada utilizando-se o programa estatístico Multiv (Pillar, 2006). A diferença entre os tratamentos, com base nos dados médios de cinco avaliações e uma matriz de dados com 16 unidades amostrais para cada variável, foi testada mediante análise de variância de dados quantitativos, com testes de aleatorização para estimar o nível de significância e 10000 iterações. A medida de semelhança utilizada foi a distância euclidiana entre unidades amostrais.

\section{RESULTADOS E DISCUSSÃO}

Observou-se diferença para o teor de proteína do leite entre os tratamentos $(\mathrm{P}=0,011)$. As médias de $\%$ de proteína encontradas nos cinco períodos de avaliação mostram que o maior teor de proteína foi encontrado no tratamento em que se utilizou a pastagem de trevo como alternativa de alimentação dos animais (Tab. 1).

Tabela 1. Teores de proteína, lactose, sólidos totais e contagem de células somáticas (CCS) do leite dos animais nos tratamentos trevo branco (TB) e farelo de soja (FS), na média de cinco avaliações

\begin{tabular}{ccccc}
\hline & Proteína & Lactose & Sólidos totais & \multicolumn{2}{c}{ CCS } \\
Tratamento & $---{ }^{1}$ & $4,57 \mathrm{~b}$ & $10,40 \mathrm{a}$ & $182,88 \mathrm{a}$ \\
\hline TB & $3,02 \mathrm{a}^{1}$ & $4,64 \mathrm{a}$ & $10,39 \mathrm{a}$ & $153,53 \mathrm{a}$ \\
\hline
\end{tabular}

Médias seguidas por letras diferentes na coluna diferem entre si.

${ }^{1}$ Médias de dois dias consecutivos de controle leiteiro.

O uso da proteína - o nutriente mais caro - deve ser criterioso, considerando-se não somente sua quantidade na dieta como também sua degradabilidade no rúmen, visto que o teor de proteína do leite somente é afetado pelo teor de proteína da dieta quando estiver abaixo do mínimo recomendado (Olmos Colmenero e Broderick, 2006). O farelo de soja, muito 
utilizado nos suplementos, é rico em proteína degradável no rúmen, o que pode implicar, algumas vezes, menor eficiência na utilização do nitrogênio $(\mathrm{N})$ para a síntese proteica do leite e aumento nos custos com proteína, que muitas vezes não é aproveitada pelo animal, pois depende de fontes de carboidratos, também rapidamente degradáveis, para evitar perdas de $\mathrm{N}$ e aumentar a síntese de proteína microbiana.

Roseler et al. (1993) estudaram os efeitos de proteínas de degradabilidades diferentes sobre a produção de leite e sobre as concentrações de nitrogênio ureico do leite e do plasma sanguíneo. Observaram que duas dietas com o mesmo teor de proteína, mas de degradabilidade diferente, dão resultados diferentes não apenas em termos de produção de leite como também em relação ao teor de nitrogênio ureico do leite e do plasma, ou seja, afetando o teor de proteína do leite. Alta quantidade no teor de nitrogênio nos fluidos do animal reflete não só em alto nível de proteína na dieta como também em baixa eficiência no aproveitamento da proteína degradável no rúmen, resultando em valores menores de seu teor no leite.

O uso de proteína menos degradável no rúmen pode aumentar o teor de proteína do leite, a produção de leite e a produção de proteína (Mühlbach et al., 2000; Kalscheur et al., 2006; Mikolayunas et al., 2011). Por outro lado, o uso de dietas com excesso de proteína não degradável no rúmen pode diminuir o teor de proteína do leite e o volume de leite produzido, em função da diminuição da síntese de proteína microbiana no rúmen, devido à falta de amônia para as bactérias.

Para Poppi et al. (1990), a maior parte do N digestível nas forragens ricas em proteína bruta, em particular as leguminosas, é rapidamente degradável no rúmen, porém de menor degradabilidade que o farelo de soja, o que pode ter contribuído, no presente trabalho, para a obtenção de maior teor de proteína do leite dos animais do TB. Embora,não se tenham dados sobre a concentração de nitrogênio ureico no leite ou no sangue - que poderiam sustentar a hipótese de melhor aproveitamento da proteína fornecida na dieta com este tratamento, em detrimento de uma menor eficiência ou perda por excreção de $\mathrm{N}$ no tratamento com o farelo de soja - , pode-se inferir que a utilização de uma fonte proteica de menor degradabilidade, por meio da utilização da pastagem, contribuiu para os maiores teores de proteína no leite, observação similar à de Castillo et al. (2001). Assim, evidencia-se a importância de se otimizar a fermentação ruminal e, consequentemente, a produção microbiana. Isto pode ser alcançado com o fornecimento de volumosos de alta qualidade e com o aumento da ingestão de matéria seca dos animais, além do fornecimento de adequadas quantidades de $\mathrm{N}$ para utilização pelos microrganismos.

O teor de lactose do leite foi diferente entre os dois tratamentos $(\mathrm{P}=0,001)$, sendo o maior valor encontrado nos animais do FS (Tab. 1).

Para esta variável, obtiveram-se os valores mais elevados no tratamento em que se utilizou o farelo de soja como fonte proteica. Há uma grande unanimidade na literatura concernente ao fato de que a lactose é o componente do leite menos afetado pela alimentação. Sob condições normais, o teor é um pouco menor no início e ao final da lactação, acompanhando a curva de produção de leite. Como regra geral, a menos que os animais estejam muito subnutridos, o que não parece ter sido o caso no presente trabalho, a concentração no leite é pouco alterada por fatores nutricionais. Embora os resultados tenham apresentado diferenças significativas como ocorreu com os teores de proteína -, os valores são muito próximos, resultando em diferença muito pequena entre os tratamentos, difícil de ser interpretada em termos de diferença de rendimento comercial.

Os teores de sólidos totais (Tab. 1) mostraram-se semelhantes $(\mathrm{P}=0,909)$ entre os tratamentos $\mathrm{TB}$ e FS na média das cinco avaliações.

O teor de sólidos totais é um importante indicador da qualidade do leite, representado pela soma de todas as partes sólidas do leite consideradas, na indústria de lacticínios, como os componentes que promovem o rendimento em produtos oriundos do leite, e por meio dos quais se faz o pagamento ao produtor pelo produto entregue à indústria, principalmente gordura e proteína. Os resultados obtidos para esta variável mostram que, no tratamento em que se utilizou como alternativa de alimentação proteica o trevo branco, obteve-se o mesmo teor de sólidos totais, em relação ao farelo de soja. 
Estes resultados indicam que é possível manter ou até aumentar a qualidade do leite, em termos de componentes, mediante a utilização de uma fonte de alimento proteico mais viável economicamente. Esta alternativa difere do que é praticado frequentemente pelos produtores de leite, que consiste na utilização de uma fonte mais cara de proteína, como é o caso do farelo de soja, a qual eleva o custo de alimentação dos animais em produção e, deste modo, reduz a margem de lucro por litro de leite produzido.

A contagem de células somáticas (Tab. 1) encontradas para os dois tratamentos foi semelhante $(\mathrm{P}=0,330)$.

Observa-se que o acesso dos animais à pastagem de trevo branco, ocasionando um curto período de tempo de permanência destes na pastagem, não produziu efeito significativo do tratamento aplicado sobre o número de células somáticas do leite, como poderia ocorrer com a manutenção das vacas em pastejo por mais tempo. De qualquer forma, os valores encontrados para ambos os tratamentos estão abaixo daqueles considerados como indicadores de mastite subclínica, detectada por meio da CCS do leite dos animais, indicando que os animais não apresentam problemas de saúde e que o leite está dentro dos parâmetros de qualidade considerados pela legislação.

Dessa forma, pode-se dizer que a utilização da pastagem de trevo branco, como uma alternativa de fornecimento de alimento proteico aos animais em substituição ao farelo de soja, foi viável, por permitir a obtenção de resultados semelhantes aos obtidos com o manejo alimentar tradicional praticado pelos produtores, que é o fornecimento de suplemento proteico baseado no uso de concentrados, os quais tendem a aumentar o custo com a alimentação das vacas leiteiras.

\section{CONCLUSÕES}

É possível a substituição de farelo de soja, na alimentação de vacas Holandesas em pastagens de azevém, por pastejo controlado de trevo branco, sem alterar o teor de sólidos totais e a contagem de células somáticas do leite produzido. A utilização de trevo branco tem influência positiva no teor de proteína, porém o teor de lactose é inferior. Os indicadores de qualidade do leite, no seu conjunto, indicam que a utilização do pastejo de trevo branco é viável e eficiente, em razão da possibilidade de redução de custo na suplementação concentrada proteica.

\section{AGRADECIMENTOS}

Á Prefeitura Municipal de Camargo/RS, ao $\mathrm{CNPq}$ e ao Condomínio Nova Era, pela viabilização financeira e pelo apoio na execução do experimento.

\section{REFERÊNCIAS}

ANDRADE, L.M.; EL FARO, L.; CARDOSO, V.L. et al. Efeitos genéticos e de ambiente sobre a produção de leite e a contagem de células somáticas em vacas holandesas. Rev. Bras. Zootec., v.36, p.343-349, 2007.

BARGO, F.; MULLER, L.D.J.E.; DELAHOY, J.E.; CASSIDY, T.W. Milk response to concentrate supplementation of high producing dairy cows grazing at two pasture allowances. $J$. Dairy Sci., v.85, p.1777-1792, 2002.

BARGO, F.; REARTE, D.H.; SANTINI, F.J.; MULLER, L.D.J.E. Ruminal digestion by dairy cows grazing winter oats pasture supplemented with different levels and sources of protein. $J$. Dairy Sci., v.84, p.2260-2272, 2001.

CARVALHO, P.C.F.; TRINDADE, J.K.; MEZZALIRA, J.C. et al. Do bocado ao pastoreio de precisão: Compreendendo a interface plantaanimal para explorar a multifuncionalidade das pastagens. Rev. Bras. Zootec., v.38, p.109-122, 2009.

CASTILLO, A.R.; KEBREAD, E.; BEEVER, D.E.; FRANCE, J. A review of efficiency of nitrogen utilisation in dairy cows and its relationship with the environmental pollution. $J$. Anim. Feed Sci., n.9, p.1-32, 2000.

CASTILlO, A.R.; KEBREAD, E.; BEEVER, D.E. et al. The effect of protein supplementation on nitrogen utilization in lactating dairy cows fed grass silage diets. J. Anim. Sci., v.79, p.247-253, 2001.

FERNANDES, M.F.; QUEIROGA, R.C.R.E.; MEDEIROS, A.N. et al. Características físicoquímicas e perfil lipídico do leite de cabras mestiças Moxotó alimentadas com dietas suplementadas com óleo de semente de algodão ou de girassol. Rev. Bras. Zootec., v.37, p.703710, 2008. 
FONTANELI, R.S.; SOLLENBERGER, L.E.; LITTELL, R.C.; STAPLES, C.R. Performance of Lactating Dairy Cows Managed on PastureBased or in Freestall Barn-Feeding Systems. J. Dairy Sci., v.88, p.1264-1276, 2005.

IPAGRO. Seção de Ecologia Agrícola. Atlas agroclimático do Estado do Rio Grande do Sul. Porto Alegre: Secretaria da Agricultura, 1989. 210p.

KALSCHEUR, K.F.; BALDWIN, R.L.; GLENN, B.P.; KOHN, R.A. Milk Production of Dairy Cows Fed Differing Concentrations of Rumen-Degraded Protein. J. Dairy Sci., v.89, p.249-259, 2006.

MARTINEZ, J.L.; LÓPEZ, J. Utilização de silagem de milho com ureia e de trevo branco no arraçoamento de vacas em lactação durante período outonal. Rev. Soc. Bras. de Zootec., v.20, p.550-560, 1991.

MATTOS, W.R.S.; PEDROSO, A.M. Influência da nutrição sobre a composição de sólidos totais de leite. In: SIMPÓSIO SOBRE BOVINO DE LEITE, 5., 2005, São Paulo. Anais... Piracicaba: FEALQ, 2005. p.103-129.

MIKOLAYUNAS, C.; THOMAS, D.L.; ARMENTANO, L.E.; BERGER Y.M. Effect of rumen-undergradable protein supplementation and fresh forage composition on nitrogen utilization of dairy ewes. J. Dairy Sci., v.94, p.416-425, 2011.

MORENO, J.A. Clima do Rio Grande do Sul. Porto Alegre: Secretaria da Agricultura, 1961, $42 \mathrm{p}$.

MÜHLBACH, P.R.F.; OSPINA, H.; PRATES, E.R.; BARCELLOS, J.O.J. Aspectos nutricionais que interferem na qualidade do leite. In: ENCONTRO ANUAL DA UFRGS SOBRE NUTRIÇÃO DE RUMINANTES, 2., 2000. Porto Alegre. Anais... Porto Alegre: Departamento de Zootecnia da UFRGS, 2000. p.73-102.

OLIVEIRA, M.A.; REIS, R.B.; LADEIRA, M.M. et al. Produção e composição do leite de vacas alimentadas com dietas com diferentes proporções de forragem e teores de lipídeos. Arq. Bras. Med. Vet. Zootec., v.59, p.759-766, 2007.
OLMOS COLMENERO, J.J.; BRODERICK, G.A. Effect of Amount and Ruminal Degradability of Soybean Meal Protein on Performance of Lactating Dairy Cows. J. Dairy Sci., v.89, p.1635-1643, 2006.

PEDROSO, A.M.; SANTOS, F.A.P.; BITTAR, C.M.M. Substituição do milho em grão por farelo de glúten de milho na ração de vacas em lactação em confinamento. Rev. Bras. Zootec., v.38, p.1614-1619, 2009.

PEYRAUD, J.L.; DELABY, L. Ideal concentrate feeds for grazing dairy cows. Responses to supplementation in interaction with grazing management and grass quality. In: GARNSWORTHY, P.C.; WISEMAN, J. (Eds.). Recent advances in Animal Nutrition. Nottingham: Nottingham University Press, 2001. p.203-220.

PILLAR, V.P. (Ed.). Multiv: Multivariate Exploratory Analysis, Randomization Testing and Bootstrap Resamplimg. User's Guide. Porto Alegre: UFRGS, 2006. 51p.

PINA, D.S.; VALADARES FILHO, S.C.; VALADARES, R.F.D. et al. Consumo e digestibilidade aparente total dos nutrientes, produção e composição do leite de vacas alimentadas com dietas contendo diferentes fontes de proteína. Rev. Bras. Zootec., v.35, p.1543-1551, 2006.

POPPI, D. Manipulation of nutrient supply to animals at pasture. Opportunities and consequences. In: ANIMAL SCIENCE CONGRESS, 5., 1990, Taipei. Proceedings... Taipei: AAAP, 1990. p.41-79.

RIBEIRO FILHO, H.M.N.; HEYDT, M.S.; BAADE, E.A.S.; THALER NETO, A. Consumo de forragem e produção de leite de vacas em pastagem de azevém-anual com duas ofertas de forragem. Rev. Bras. Zootec., v.38, p.2038-2044, 2009.

ROSELER, D.K.; FERGUSON, J.D.; SNIFFEN, C.J.; HERREMA, J. Dietary protein degradability effects on plasma and milk urea nitrogen and milk nonprotein nitrogen in Holstein cows. J. Dairy Sci., v.76, p.525-534, 1993.

RYAN, W.; HENNESSY, D.; MURPHY, J.J. et al. A model of nitrogen efficiency in contrasting grass-based dairy systems. J. Dairy Sci., v.94, p.1032-1044, 2011. 
SANTOS, F.A.P.; JUCHEM, S.O. Sistemas de produção de leite à base de forrageiras tropicais. In: FONTANELI, R.S.; DÜRR, J.W. (Eds.). Sistemas de produção de leite. Passo Fundo: UPF, 2001. p.22-36.

SANTOS, F.A.P.; MARTINEZ, J.C.; VOLTOLINI, T.V. et al. Utilização da Suplementação com Concentrado para Vacas em Lactação Mantidas em Pastagens Tropicais. In: SIMPÓSIO GOIANO SOBRE MANEJO E NUTRIÇÃO DE BOVINOS DE CORTE E LEITE, 5., 2003, Goiânia. Anais... Goiânia: CBNA, 2003. p.289-346.

SILVA, S.C.; NASCIMENTO JR, D.; MONTAGNER, D.B. Desafios da produção intensiva de bovinos de corte em pastagens. In: I SIMBOI - SIMPÓSIO SOBRE DESAFIOS E NOVAS TECNOLOGIAS NA BOVINOCULTURA DE CORTE, 1., 2005, Brasília. Anais... Brasília: UPIS, 2005. p.23-28.
STOCKDALE, C.R. Levels of pasture substitution when concentrates are fed to grazing dairy cows in northern Victoria. Aust. J. Exp. Agr., v.40, p.913-921, 2000.

VILELA, D.; FERREIRA, A.M.; RESENDE, J.C. et al. Efeito do concentrado no desempenho produtivo, reprodutivo e econômico de vacas da raça Holandesa em pastagem de coast-cross. Arq. Bras. Med. Vet. Zootec., v.59, p.443-450, 2007.

VILELA, D.; LIMA, J.A.; RESENDE, J.C. et al. Qualidade do leite produzido por vacas holandesas em pastagem de coast-cross suplementada com concentrado. Bol. Ind. Anim., v.62, p.221-228, 2005.

WILKINS, R.J.; GIBB, M.J.; HUCKLE, C.A. et al. Effect of supplementation on production by spring-calving dairy cows grazing swards of differing clover content. Grass Forage Sci., v.49, p.465-475, 1994. 